\title{
A theoretical framework for measuring the quality of student learning in outcomes-based education
}

\author{
R Killen* and S A Hattingh \\ University of Newcastle (Australia) and University of Pretoria
}

\begin{abstract}
The most important principles of outcomes-based education (OBE) is that planning, teaching and assessment should focus on helping learners to achieve significant outcomes to high standards. This cannot be achieved without having suitable ways to describe desired learning outcomes and the quality of students' demonstrations of learning. This article outlines a systematic approach to defining outcomes and describing the relationship between learners' responses to assessment items and their levels of understanding. The approach is based on the Structure of the Observed Learning Outcome (SOLO) taxonomy with multimodal functioning - a means of analysing learner understanding that is based on modes of thinking, forms of knowledge and ways of structuring knowledge.
\end{abstract}

\section{INTRODUCTION}

Outcomes-based education (OBE) has four simple principles. The first principle, sometimes referred to as clarity of focus, is that education systems should be organised so that teachers and learners can focus clearly, consistently, systematically and creatively on the important outcomes that learners are to achieve. To be important, outcomes should require 'high-quality, culminating demonstrations of significant learning in context' (Spady 1994:18).

The second principle is called designing back and it is inextricably linked to the first principle. It means that the starting point for curriculum design must be a clear definition of the significant learning that students are to achieve. Once this required learning has been defined, important instructional decisions can be made by tracing back from this 'desired end-result' and identifying enabling outcomes that will assist learners to achieve the broader long-term outcomes. This does not mean that curriculum design or implementation should be simple linear processes, but it does mean that there should be direct and explicit links between all planning, teaching and assessment decisions and the significant outcomes that students are ultimately to achieve.

The third principle of OBE is that teachers should have high expectations for all students; they should expect all students to achieve significant outcomes to high

R Killen, University of Newcastle, Faculty of Education and Arts, University Drive, CALLAGHAN NSW 2308, Australia

Tel: 61249537043 e-mail: roy.killen@newcastle.edu.au 
standards. From this perspective, depth of understanding and intellectual rigour are not reserved for a few learners; they are expected of all learners. This provides a link to the fourth principle - that teachers must strive to provide expanded learning opportunities for all learners in recognition of the fact that not all learners can learn the same things in the same way or in the same time (Spady 1994).

When we consider the implications for assessment embedded in these principles it becomes clear that our starting point must be an explicit alignment between the outcomes we want learners to achieve and the methods we use to assess and report that learning. If outcomes are to be demonstrations of significant, contextualised learning rather than trivial statements expressed in narrow behavioural terms, this alignment requires a very careful consideration of how learning should be described. Educators have long accepted that 'learning is not only adding something to our knowledge' (Danner 1995:242); learning is a process of developing understanding by integrating new knowledge into the learner's world of sense and meaning. Therefore, we need to have appropriate ways to describe whatever it is that we want students to understand and appropriate ways to measure their understanding so that we will know when our teaching has been successful.

An important consequence of directing our attention towards the assessment of complex outcomes is that it changes the focus of assessment from quantity to quality. It changes our focus from asking 'How many objective questions can the learner answer?' or 'Which particular skills can the learner demonstrate?' to asking 'How well does the learner understand important concepts, theories and principles?' and 'How expertly can the learner integrate a range of skills into a complex performance?' Descriptions of the difference between high-quality and low-quality achievement of complex outcomes in words rather than numbers can provide criteria by which to judge the quality of students' learning. From this quality perspective, 'understanding (rather than memorisation), creativity (rather than reproduction), diversity (rather than conformity), initiative (rather than compliance) and challenge (rather than blind acceptance) become the yardsticks by which we try to measure, describe and report student learning' (Killen 2003:10). The remainder of this article explores some of the implications and practicalities of such an approach to assessment. It is an attempt to provide 'a framework of theory to ensure that assessment is an effective link between pedagogy and quality of learning and performance' (Imrie 1995:176).

\section{DESCRIBING THE DEVELOPMENT AND STRUCTURE OF LEARNING}

Demonstrations of learning depend upon the learner's understanding. If that understanding is shallow, the demonstration of learning cannot be complex or sophisticated. It is, therefore, crucial that we define what we mean by understanding and how we intend to differentiate between high and low levels of understanding before we try to assess learners' achievement of any outcome. Put simply, you cannot assess what you cannot define. Understanding may be 
regarded as the ability to provide explanations, or the ability to think logically, or the ability to solve unfamiliar problems, or the ability to reinterpret objective knowledge, or the ability to view things from multiple perspectives - to mention just a few possibilities. A particular educator's idea of what it means to 'understand' will influence the way that person tries to help learners to understand and how they attempt to assess their learners' understanding.

Our efforts to clarify what we mean by understanding and learning cannot be made in isolation from the particular content we want learners to master. For example, it would be pointless to try to assess a learner's 'understanding of mathematics' unless we first delineated the area of mathematics in which we were interested (perhaps calculus). We could then consider what it means to 'understand calculus'. This would quickly lead us to consider some of the specific aspects of calculus that we wanted students to understand and this would lead us to consider how we wanted learners to be able to think about and manipulate specific content (concepts, principles, theories, and so on). Such thinking will lead us to consider what realistic expectations we should have for learners at different stages of their learning. For example, we would expect undergraduate engineering students to have a deeper 'understanding of calculus' than the understanding we would expect of school students sitting for a matriculation examination. However, unless we can define what that difference in understanding should be, we cannot teach for it or assess it. To address these complex issues we need to give some attention to how people learn. In doing so, we need to be aware that there is no universally accepted theory of how children or adults learn; rather, there are several well accepted, although sometimes conflicting, theories (Wood 1998). The theory we choose to follow will determine how we conceptualise understanding and how we try to assess learning.

For the purpose of this article, we will consider the neo-Piagetian approach to cognitive development because it provides a feasible explanation of learning across a wide range of situations (school, university, different subjects, and so on). Using this approach, learning can be described in terms of three characteristics: (1) the mode of cognitive functioning, (2) the forms of knowledge that are developed and (3) the ways that learners structure their knowledge. Collis (1992) suggests that modes of cognitive functioning progress from sensori-motor through iconic, concrete-symbolic and formal to post-formal. Each mode represents a distinct (measurable) advance in the development of cognition and learning competence. Each mode of cognitive functioning enables the learner to deal with a different form of knowledge. The form of knowledge in the sensori-motor mode is usually described as tacit knowledge - knowing how to perform a skilled act without necessarily being able to describe the act or explain why it is done in a particular way. From the perspective of teaching and assessment, two things should be noted about this mode of cognitive functioning: it forms the basis for progression to the next mode (iconic) and it encompasses a wide range of different levels of tacit knowledge. For example, both the knowledge underpinning very simple skills 
performed by young children and the knowledge underpinning more complex activities (such as hitting a golf ball) all require tacit knowledge.

The iconic mode is so named because it is the stage of development during which learners gain (and later further develop) the capacity to form internal pictures, images or 'icons' and to use words to represent real objects and to facilitate thought. Capacity for this form of thought commences at about 18 months and it allows the learner to use signifiers (words, images, etc.) to manipulate ideas and to communicate orally. Development continues within this mode when, for example, communication reaches adult level in terms of its structure and sophistication. Iconic thinking facilitates the development of intuitive knowledge that enables learners to do things (such as object classification) correctly, but does not enable them to explain why. Further maturity within this mode of thinking facilitates quite sophisticated activities such as art appreciation and problem solving in areas such as mathematics and science - when 'the "solution" to the problem is imaged in this mode and then established to the satisfaction of colleagues by evidence and argument in a later-developed mode, usually formal' (Collis 1992:28).

The concrete-symbolic mode is so-named because it allows the learner to interpret the concrete world through symbolic systems. It represents an important development in the abstraction involved in thinking. Mental representations are now in terms of concepts rather than icons and the logical relationships between concepts allow learners to manipulate them. This mode of cognition is possible from about 6 years of age. Because the learner can now deal with symbolic systems, such as those used in language, mathematics and music, he or she can now think about events and objects from the environment in symbolic ways. For example, the leaner can use geometric diagrams to represent physical objects and events.

Learning in the concrete-symbolic mode leads to the development of declarative knowledge - the ability to give symbolic descriptions of the concrete world. Mastery of the symbol systems involved in writing, computational mathematics, drawing and reading maps, reading musical scores and so on provides learners with a powerful tool for controlling their interactions with the environment. 'The mastery of these systems, and their application to reality, must be regarded as a major task to be achieved during the years of compulsory schooling' (Collis 1992:29). Most importantly, learners must come to understand that 'there is a logic and order between the symbols they are using [such as grammatical rules in language or mathematical symbols in an equation] that allows the symbols to be manipulated independently of the aspect of the real world that they are representing at that point in time' (Collis 1992:28). Manipulation of the symbols can lead to more appropriate symbolic representations and to a deeper understanding of the real world. 'Ability to function efficiently in the skills of this mode is crucial to operating effectively within our society because it is the mode in which the cognitive aspects of everyday living are conducted' (Collis \& Biggs 
1991:189). If learners are to develop intellectually in the concrete symbolic mode (and higher modes), teachers must actively cultivate the learner's intellectual skills rather than just impart knowledge. Likewise, teachers need to assess their learners' intellectual skills, not just their capacity to memorise information.

The formal mode involves the manipulation of theoretical (abstract) constructs, hence it is concerned with theoretical knowledge. Thinking can now involve hypothesis formulation and propositional reasoning - the learner can now consider possibilities as well as realities. Development in this mode is usually contentspecific - a learner may be capable of formal operation in mathematics but not in music, for example. This mode usually starts around age 16 and is a commonly expected level for successful university entrance (Collis \& Biggs 1983). It is expected that development in this mode will continue through university and that 'a high level of functioning in this mode in the student's major study areas' is a minimum passing standard in a Bachelor's degree and at this level learners should be able to 'demonstrate their understanding of a discipline well enough to work within it' (Collis \& Biggs 1991:189).

Development in the post-formal mode is very content-specific and few learners will reach this stage - those who do will probably not reach it until adulthood. Collis and Biggs (1991:189) suggest that individuals who aspire to the postformal mode must have an overview of their discipline such that they can challenge its basic tenets and conduct research to advance understanding in the area'. This is the form of cognition that we usually expect of postgraduate students.

The model outlined above departs from the traditional Piagetian interpretation of cognitive development in that it proposes that the modes are cumulative rather than sequential - as each successive mode develops, it exists alongside its predecessors rather than replacing its immediate predecessor. This has important implications for how we teach and how we assess learners. Collis (1992:26) points out that this view of cognitive development emphasises two important concepts: firstly, as an individual matures and becomes capable of a higher mode of cognition, 'the mode(s) developed earlier continue to develop on the foundation of an increasingly mature physical and intellectual background' and, secondly, 'as the modal repertoire increases, multimodal functioning becomes the norm'. Because of this, each mode of cognition and each form of knowledge are important at all levels of education - particularly in higher education. We need to consider this when formulating outcomes, when facilitating learning and when assessing learner achievement. Because learners can deal with different forms of knowledge simultaneously, learners may choose to use any of the forms of knowledge or modes of thinking that are available to them. The educator's challenge is to encourage and assist learners to use appropriate modes of thinking and then to develop assessment techniques that provide learners with opportunities to demonstrate appropriate forms of knowledge and modes of thinking.

This way of describing cognition is helpful, but it is not complete - it does not provide sufficient explanation of how thinking occurs within each mode or what 
needs to happen in order for thinking to progress from one mode to a higher mode. To get a more complete picture of how students learn and why they respond in particular ways to the questions we ask them, we need to consider how they structure their thinking. Many teachers, particularly in the senior years of school and in higher education, intuitively consider structure when making qualitative judgements about learners' written work. For example, they might look for the logical development of an argument in an essay. However, in order to draw valid inferences from assessment evidence and to provide useful feedback to learners, we need a systematic way of describing how we arrive at these qualitative judgements. For example, how we decide that an argument is logical. One such system is the SOLO taxonomy. SOLO is an acronym for Structure of the Observed Learning Outcome and the taxonomy was developed to provide 'a general framework for systematically assessing quality [of learning]' (Collis \& Biggs 1986:1).

The SOLO taxonomy enables teachers to make inferences about the depth of learners' understanding by examining the way they structure their oral or written responses to open-ended questions. (A response may be anything from a short oral answer to a lengthy essay.) Biggs and Collis (1980) suggested that there are five distinctive ways in which a learner might structure a response - these became known as the five levels of the SOLO taxonomy. These levels are pre-structural, uni-structural, multi-structural, relational and extended abstract. (There are transitional levels between each of the five main levels, but they will not be considered here.) The five levels progress in complexity in terms of the cognitive capacity needed to answer the question, the attempts the learner makes to relate his or her response to the question, the internal consistency of the answer, the closure of the answer and the overall structure of the answer. The main characteristics of the five levels of the taxonomy can be summarised as follows:

When giving a pre-structural response the learner either does not engage with the task ('I don't know'), simply repeats information given in the question, or guesses the answer. Attempted responses usually contain inconsistencies, both within the response and between the data and the responses. Any structure in the response is personal to the learner and any links with the given data are irrelevant. Justification for such responses is likely to be personal and subjective (e.g., 'The answer just looks right to me'.)

A uni-structural response draws a simple correct conclusion, but is based on only one relevant aspect of the given data. It is typical of a learner who feels strongly that they need to come to a quick decision, so they reach closure rapidly and tend to disregard possible inconsistencies in their answer.

A multi-structural response uses two or more pieces of given data to reach a correct conclusion. It may contain elements that are consistent with the question or data, but which lack integration with one another.

A relational response builds on the multi-structural response by using a previously learnt concept or principle to integrate the multiple ideas and to explain 
the links between them. However, since understanding of the broad principle may be limited, such responses may be inconsistent across different contexts.

An extended abstract response goes beyond what has been taught and uses logical deduction to frame the answer. To produce an extended abstract response, the learner must not only attend to given information but must consider its relevance to overriding abstract principles and deduce an hypothesis that can be applied to a situation that is not given. Such responses will show consistency internally, externally, and across different contexts. Because the learner will feel a great need for consistency, they will tend to utilise all available data and their conclusions will be more open. Such responses are likely to be qualified to take account of particular contexts or mention the possibility of different interpretations or mitigating circumstances. Extended abstract responses may contain statements such as 'The answer depends on how you interpret the data. If the interpretation is based on . . . it would lead to the conclusion that ....

The purpose of using the SOLO taxonomy is to provide learners with a detailed description of their current understanding of some particular fact, concept, principle or process - the purpose is not to label learners (as high or low achievers). There is always an expectation that a learner's response can improve through instruction and/or experience. This notion of 'capacity for continual improvement' is consistent with one of the basic principles of OBE - all learners can succeed if they have appropriate opportunities and time to learn (Spady 1994).

One of the advantages of using the SOLO taxonomy as a framework for describing the quality of student learning is that it helps students to understand what teachers are looking for when they mark assessment tasks. The progression from an answer based on just one relevant piece of information, to one based on several relevant pieces of information, to one that relates this information to an integrating principle can be understood by concrete-symbolic thinkers. Learners capable of formal mode thinking can understand the final step of recognising the importance of context and the possibility of multiple alternatives.

The following example gives a brief illustration of how the SOLO taxonomy can be used to classify learners' responses - it is based on an example in Killen (in press).

Question: Explain why cheetahs have spots.

\begin{tabular}{|c|c|c|}
\hline $\begin{array}{c}\text { Examples of possible } \\
\text { answers }\end{array}$ & $\begin{array}{l}\text { Characteristics of the } \\
\text { sample answer }\end{array}$ & SOLO 'level’ descriptor \\
\hline $\begin{array}{l}\text { (1) 'I don't know.' } \\
\text { (2) 'So that they are dif- } \\
\text { ferent from lions.' }\end{array}$ & $\begin{array}{l}1 \text { No attempt to answer } \\
\text { the question. } \\
2 \text { The response is irrele- } \\
\text { vant. }\end{array}$ & $\begin{array}{l}\text { Pre-structural-there is no } \\
\text { structure to the answer. }\end{array}$ \\
\hline
\end{tabular}




\begin{tabular}{|l|l|l|}
\hline \multicolumn{1}{|c|}{$\begin{array}{c}\text { Examples of possible } \\
\text { answers }\end{array}$} & \multicolumn{1}{c|}{$\begin{array}{c}\text { Characteristics of the } \\
\text { sample answer }\end{array}$} & SOLO 'level' descriptor \\
\hline $\begin{array}{l}\text { 'Because it makes them } \\
\text { hard to see when they are } \\
\text { stalking prey.' }\end{array}$ & $\begin{array}{l}\text { The statement is true, but it } \\
\text { focuses on just one factor } \\
\text { that results from the spots, } \\
\text { it does not attempt to } \\
\text { explain the cause or ex- } \\
\text { plore any evolutionary link } \\
\text { between the cause and the } \\
\text { effect. }\end{array}$ & $\begin{array}{l}\text { Uni-structural } \text { - the an- } \\
\text { swer focuses on just } \text { one } \\
\text { relevant fact. }\end{array}$ \\
\hline $\begin{array}{l}\text { 'The spots are formed by } \\
\text { melanin in the skin. Chee- } \\
\text { tahs have spots so that } \\
\text { they will be camouflaged } \\
\text { in their normal hunting } \\
\text { environment.' }\end{array}$ & $\begin{array}{l}\text { Both the points mentioned } \\
\text { are correct, but no attempt } \\
\text { is made to explain them or } \\
\text { relate them. }\end{array}$ & $\begin{array}{l}\text { Multi-structural - the an- } \\
\text { swer is based on several } \\
\text { relevant concrete details. }\end{array}$ \\
\hline $\begin{array}{l}\text { 'Dark skin areas on ani- } \\
\text { mals are produced by } \\
\text { melanin. The spread of the } \\
\text { melanin is determined by } \\
\text { the biological switching on } \\
\text { and off a chemical reaction } \\
\text { as the embryo develops. In } \\
\text { cheetahs, the melanin pro- } \\
\text { ducing reaction is turned } \\
\text { on for just a short time. } \\
\text { Cheetahs probably } \\
\text { evolved this way after a } \\
\text { chance mutation because it } \\
\text { suited their hunting envir- } \\
\text { onment.' }\end{array}$ & $\begin{array}{l}\text { The simple biological ex- } \\
\text { planation is correct and } \\
\text { some attempt is made to } \\
\text { link it to probable evolu- }\end{array}$ & $\begin{array}{l}\text { Relational - the answer } \\
\text { focuses on ideas that relate } \\
\text { all the relevant details. }\end{array}$ \\
\hline $\begin{array}{l}\text { 'Dark skin areas are pro- } \\
\text { duced by melanin. The } \\
\text { size and shape of the } \\
\text { embryo during the time } \\
\text { when the melanin produc- } \\
\text { tion is occurring deter- } \\
\text { mines whether an animal } \\
\text { has spots, stripes or no }\end{array}$ & $\begin{array}{l}\text { The answer contains all } \\
\text { the relevant points, briefly } \\
\text { explains how they are } \\
\text { related, and mentions other } \\
\text { abstract ideas that were not } \\
\text { part of the original ques- } \\
\text { tion. }\end{array}$ & $\begin{array}{l}\text { Extended abstract - the } \\
\text { answer uses abstract prin- } \\
\text { ciples to explain the rela- } \\
\text { tionships and it recognises } \\
\text { other possibilities. }\end{array}$ \\
\hline
\end{tabular}




\begin{tabular}{|c|c|c|}
\hline $\begin{array}{l}\text { Examples of possible } \\
\text { answers }\end{array}$ & $\begin{array}{l}\text { Characteristics of the } \\
\text { sample answer }\end{array}$ & SOLO 'level' descriptor \\
\hline $\begin{array}{l}\text { pattern. The melanin starts } \\
\text { at points on the skin and } \\
\text { spreads to form spots. } \\
\text { Long, thin body parts like } \\
\text { the cheetah's tail develop } \\
\text { stripes because the spots } \\
\text { merge. In evolutionary } \\
\text { terms, the spots probably } \\
\text { started as a mutation that } \\
\text { gave cheetahs an advan- } \\
\text { tage when hunting, so } \\
\text { natural selection deter- } \\
\text { mined which ones passed } \\
\text { on the advantageous } \\
\text { genes. In their particular } \\
\text { hunting environment, } \\
\text { stripes were not an advan- } \\
\text { tage and that is one reason } \\
\text { why mutations such as the } \\
\text { "king" cheetah are rare in } \\
\text { the wild. The skin colours } \\
\text { of animals (like cheetahs) } \\
\text { are examples of mathema- } \\
\text { tical patterns that can be } \\
\text { described with partial dif- } \\
\text { ferential equations.' }\end{array}$ & $\begin{array}{l}\text { This answer indicates that } \\
\text { the student is capable of } \\
\text { extended abstract thought. } \\
\text { However, it is still a very } \\
\text { brief response that does } \\
\text { not provide all the detail } \\
\text { that would normally be } \\
\text { expected in an extended } \\
\text { abstract response. }\end{array}$ & \\
\hline
\end{tabular}

This example illustrates the importance of deciding in advance what level of understanding is required. A Grade 6 teacher, for example, might not expect learners to have anything more than a multi-structural level of understanding. She might have an outcome such as: 'Learners will be able to give simple biological and environmental reasons for animals having different skin colours'. A Grade 12 teacher, however, might expect students to have a relational level of understanding. She might have an outcome such as: 'Learners will be able to explain how various genetic factors determine the skins colorations of animals'. At undergraduate level, an outcome designed to encourage extended abstract thinking might be: 'Learners will be able to compare various theories about how biological and environmental factors interact to produce animal characteristics that are inherited'.

The method of analysing learner responses illustrated in the above example can 
be applied in any learning area. Biggs and Collis (1982) provide examples of how the SOLO taxonomy can be used to classify responses to questions in mathematics, history, geography, poetry and modern languages (mainly in the school context). Killen (1984) provides examples from several fields of vocational education. Collis, Jones, Sprod, Watson and Fraser (1998) describe detailed examples from physics. The authors have used the taxonomy for evaluating students in education, technology and business studies at two South African universities. The basic process is for the teacher to identify which facts, concepts, principles and relationships they expect learners to understand and be able to explain and then structure questions that will give learners an opportunity to provide the required type of answer. If your question asks learners to 'name' or 'identify' it will solicit nothing more than a uni-structural response. If it asks them to 'describe' or 'classify' it will encourage a multi-structural response. If it asks them to 'explain' or 'analyse' it will encourage a relational response. It is unlikely that students will give an extended abstract response unless they are asked to do things such as 'predict', 'hypothesise' or 'reflect'.

If we combine the SOLO taxonomy with the modes of thinking and forms of knowledge model described earlier in this article it produces a model that Biggs \& Collis (1991) refer to as the SOLO taxonomy with multimodal functioning. It can be represented as shown in Figure 1.

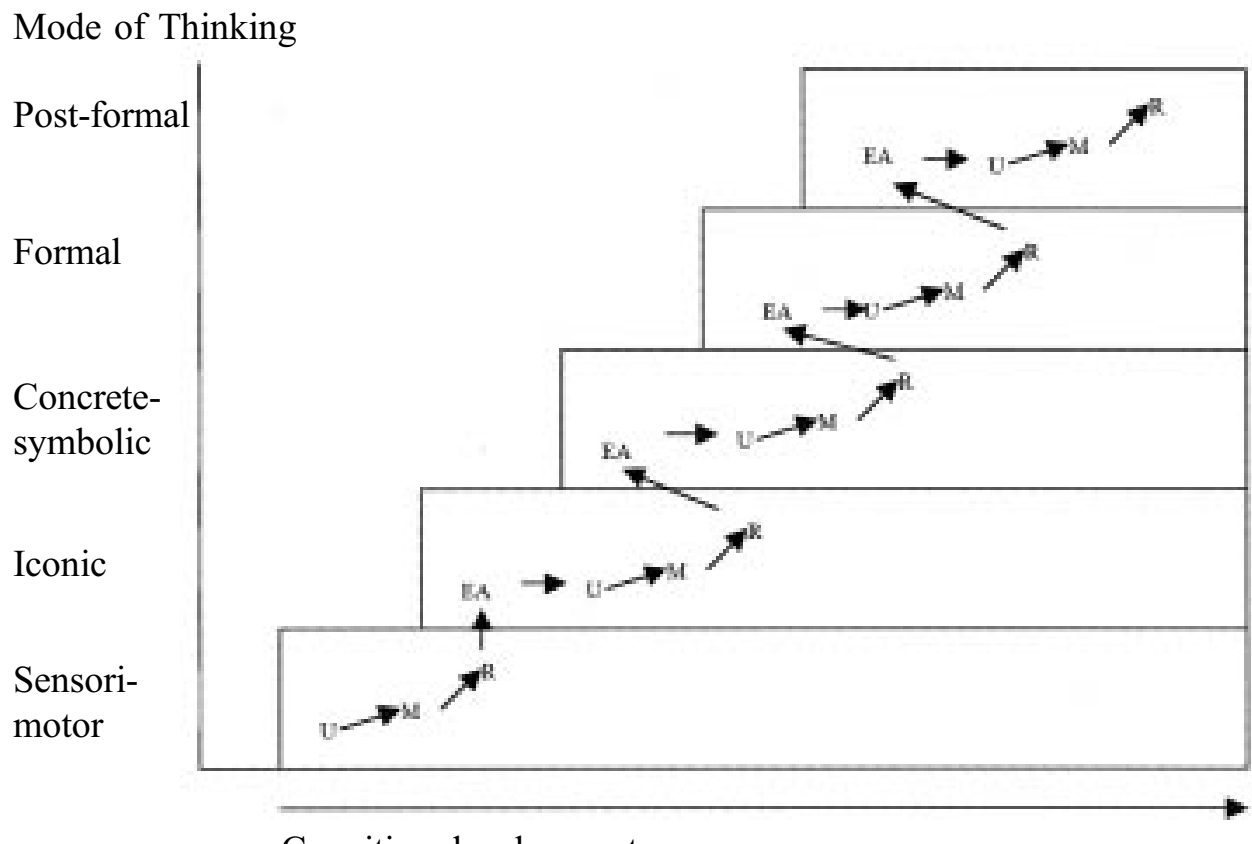

Cognitive development

Figure 1: The SOLO taxonomy with multimodal functioning (adapted from Biggs \& Collis 1991). 
This model suggests that within each mode of functioning (iconic, concretesymbolic, etc.) learning develops in sequences:

(1) uni-structural (U) in which individual pieces of knowledge or skills are used separately;

(2) multi-structural (M) in which several skills or cognitive constructs are used (usually sequentially); and

(3) relational (R) in which the skills and knowledge are used systematically under the guidance of some integrating concept.

Once the learner has mastered the content and thinking strategies at the relational level, this integrated 'unit' of understanding can become a uni-structural response for a more sophisticated U-M-R cycle of learning within the same mode. For example, Watson, Collis and Campbell (1995) found that some learners went through a U-M-R cycle to develop a basic understanding of fractions and then were able to use that understanding as the (uni-structural) basis for a further U-M$\mathrm{R}$ cycle in which they learned to apply their understanding of fractions to problem solving - all of this within the concrete-symbolic mode of thinking.

If there is sufficient complexity in the knowledge with which learners are dealing in one mode, then some learners will be able to develop extended abstract (EA) responses that actually take them to the next (higher) mode. If they are then able to consolidate the complex relationships from the lower mode with a higherorder principle, they can formulate a uni-structural response in the higher mode. In these ways, learners can progress to higher levels within each mode and from one mode to the next.

Although the model in Figure 1 does not show pre-structural responses, they are possible - learners who are required by the assessment process to operate in a particular mode (say, formal) may give a response that does not demonstrate elements of that mode.

The detail of what constitutes a particular mode of functioning (e.g., concretesymbolic) and what constitutes a particular level of response (e.g., relational) will be very discipline/subject/topic specific. It will also depend on the extent to which the instruction and assessment are cross-discipline. Watson, Campbell \& Collis (1999) illustrated this point very well in their investigation of children's understanding of fractions combined with their understanding of the concept of fairness.

\section{FOCUSING ASSESSMENT ON QUALITY LEARNING}

The SOLO multimodal model provides a language for describing and communicating desired outcomes and it provides a method for developing standards against which to compare student achievement. Our starting point for assessment should always be the question: 'What did we want the students to learn?' because 
until we have answered that question clearly we cannot decide what to assess or how to assess it. The next question to ask is: 'What would a learner have to do to convince me that she had learned what I wanted her to learn?' A detailed answer to that question should describe the assessment task and the standard to which the learner is required to perform the task.

The discussion so far in this article leads to the suggestion that the issues of defining learning outcomes and describing methods and standards of assessment should focus on two key concepts: the mode of cognitive functioning and the quality (or level) of functioning within the mode. If we give no thought to the mode, then we are ignoring the type of cognitive and/or psychomotor processes that are embedded in a particular outcome. If we give no thought to the level of response that is desirable, we are ignoring the quality of learning. Either of these omissions will lead to inappropriate outcome statements, inappropriate teaching strategies and learning experiences, inappropriate assessment tasks and misleading judgements about learner achievement.

Whatever the target mode of functioning or the target level of learning, we must plan instruction that will provide learners with appropriate information, experiences and opportunities to practise in that mode at that level. A simple example will illustrate this point. If we wanted to teach someone to play a drum it would be necessary to give them a lot of practice - the instruction would be focused primarily in the sensori-motor mode. If we wanted to teach them to play a piano we would have to place heavy emphasis on practice in the sensori-motor mode but we would probably also want them to be able to learn to read music - a cognitive skill in the concrete-symbolic mode (although this is not essential; some pianists cannot read music). In the case of the piano, if instruction focuses on one mode only we cannot expect the learner magically to acquire proficiency in the other mode - teaching someone to read music does not give them keyboard skills. Likewise, we can gain no information about a person's keyboard skills by simply assessing their ability to read music. In all instruction, the targeted learning (the desired outcome), the instruction and the assessment must be congruent. Anderson and Krathwohl (2001) and Killen (in press) provide guidelines for addressing this challenge.

If we use the SOLO taxonomy to assess learners, it is logical that we should also use it to report learners' achievements. This should not be done by arbitrarily assigning marks to different levels of the taxonomy. It would be meaningless, for example, simply to say that a uni-structural response should always be worth 50 per cent, a multi-structural response 60 per cent, a relational response 70 per cent, and so on. Rather, we should report student achievement by describing the things that each learner can do - descriptions that will resemble the SOLO level descriptors given earlier in this article. From these descriptions, we can develop marking rubrics to provide detailed, constructive feedback to learners about the quality of the learning that they have demonstrated. If marks (or grades) have to be allocated, they should derive their meaning from the level of understanding that 
students are able to demonstrate relative to the level that should be expected of students in the programme. In the authors' experience, marking guides developed in this way reduce the time required to assess and report on students' work, and minimise student dissatisfaction with marking. If students are given the marking guide at the same time as the question, it will usually contribute to an overall increase in the standard of students' work. The authors may be contacted for examples of this type of rubric.

\section{CONCLUSION}

One of the benefits of the SOLO multimodal model is that it provides not only an assessment tool but also a curriculum planning tool. It provides both a mechanism and a language for describing desired student learning (outcomes). Because it allows teachers to describe learning (in relation to a single outcome) across a spectrum from very basic understanding to very detailed understanding it is also a useful tool for setting or describing standards. Finally, it can guide the development of assessment procedures and specific test items.

As educators become proficient in using the SOLO multimodal model, they will find it a useful diagnostic tool. Testing just a few learners from a class can reveal a range of modes of functioning and levels of structuring knowledge that identify important concepts or ways of reasoning that need re-teaching. This type of detailed analysis of the understanding of a representative sample of students is a manageable way to obtain information about students' learning in large classes. As Watson, Campbell and Collis (1999:191) illustrate, this diagnostic testing can also highlight the 'constantly changing nature of cognitive functioning' - the process of assessment can lead to better learner understanding.

Perhaps the greatest advantage of using the SOLO taxonomy is that it opens up dialogue between teachers and students and places a clear focus on quality learning. The dialogue commences with the teacher giving students the SOLObased marking rubric at the time they receive the assessment task.

This article has not addressed directly the issue of what types of questions or assessment procedures should be used - there has been no mention of multiplechoice questions, portfolios, and so forth. The methods of assessment need to be those that best provide evidence of the learning you are trying to assess. If, for example, you want to assess uni-structural understanding in the concrete-symbolic mode then multiple-choice questions may be appropriate. However, if you want to assess relational-level understanding in the formal mode, it is most unlikely that multiple-choice questions will provide the evidence you need.

If teachers have a clear idea of what they want students to learn, and if they use appropriate means of assessing that learning, then they can be confident that the assessment results they report are meaningful. In the experience of the authors, in both Australia and South Africa, rubrics based on the SOLO taxonomy enhance the reliability and fairness of marking, thus improving the validity of the inferences 
drawn about student learning. Most importantly, these benefits are achieved without increasing the time required to mark written work such as essays.

'It is well established that teachers tend to concentrate their teaching efforts in areas of the curriculum which they can assess well' (Collis 1992:42). It is also well established that students learn well the things that teachers teach and assess well. Therefore, it is imperative that teachers teach and assess well those things that are important. A systematic application of the SOLO multimodal model will help to identify what really is important in any course of study and it will guide teachers to teach and assess these things well.

\section{REFERENCES}

Anderson, L and Krathwohl, D. 2001. A taxonomy for learning, teaching and assessing: A revision of Bloom's taxonomy of educational objectives. New York: Longman.

Biggs, J B and Collis, K F. 1980. The SOLO taxonomy. Education News 17(5):19-23.

-1982. Evaluating the quality of learning: The SOLO taxonomy (Structure of the Observed Learning Outcome). New York: Academic Press.

- 1991. Multimodal learning and the quality of intelligent behaviour, in Rowe, H, ed. Intelligence: Reconceptualisation and measurement. Hillsdale, NJ: Lawrence Erlbaum.

Collis, K. 1992. Curriculum and assessment: a basic cognitive model, in Keder, G, ed. Assessment and learning of mathematics. Hawthorn, Vic: Australian Council for Educational Research.

Collis, K and Biggs, J. 1983. Matriculation, degree requirements and cognitive demands in universities and CARS. Australian Journal of Education 27:41-51.

—. 1986. Using the SOLO taxonomy. SET: Research Information for Teachers 1(1). Australian Council for Educational Research.

- 1991. Developmental determinants of qualitative aspects of school learning, in Evans, G (ed) Learning and teaching cognitive skills. Hawthorne, Vic: Australian Council for Educational Research.

Collis, K F, Jones, B L, Sprod, T, Watson, J M and Fraser, S P. 1998. Mapping development in students' understanding of vision using a cognitive structural model. International Journal of Science Education 20(1):45-66.

Danner, H. 1995. Hermeneutics in educational discourse: foundations, in Higgs, P, ed. Metatheories in philosophy of education. Johannesburg: Heinemann.

Imrie, B W. 1995. Assessment for learning: quality and taxonomies. Assessment and Evaluation in Higher Education 20(2):175-189.

Killen, R. 1984. Applications of the SOLO taxonomy in Technical and Further Education. MEd thesis, University of Newcastle, Australia.

Killen, R. 2003. Validity in outcomes-based assessment. Perspectives in Education 21(1):1-14.

Killen, R. In press. Writing outcomes, performance indicators and assessment criteria, in Maree, K \& Fraser, W, eds. Outcomes-based assessment. Johannesburg: Heinemann.

Masters, G N. 1994. Profiles and assessment. Curriculum Perspectives 14(1):48-52.

Spady, W G. 1994. Outcome based education: critical issues and answers. Arlington, VA: American Association of School Administrators.

Watson, J M, Campbell, K J and Collis, K F. 1999. The structural development of the concept of fraction by young children. Journal of Structural Learning and Intelligence Systems 13(34):171-193. 
- 1995. Developmental structure in the understanding of common and decimal fractions. Focus on Learning Problems in Mathematics 17(1):1-24.

Wood, D. 1998. How children think and learn. Oxford: Blackwell Publishing. 